\title{
Evaluation of A Chemiluminescent Enzyme Immunoassay-Based High-Throughput SARS-CoV-2 Antigen Assay For The Diagnosis of COVID-19: The VITROS $\AA_{\text {SARS-CoV-2 Antigen Test }}$
}

\section{Nanako Matsuzaki}

Saitama Medical University: Saitama Ika Daigaku

Yuta Orihara

Saitama Medical University: Saitama Ika Daigaku

Masahiro Kodana

Saitama Medical University: Saitama Ika Daigaku Yutaro Kitagawa

Saitama Medical University: Saitama Ika Daigaku

Masaru Matsuoka

Saitama Medical University: Saitama Ika Daigaku

\section{Rieko Kawamura}

Saitama Medical University: Saitama Ika Daigaku

Shinichi Takeuchi

Saitama Medical University: Saitama Ika Daigaku

Kazuo Imai

Saitama Medical University: Saitama Ika Daigaku

Norihito Tarumoto

Saitama Medical University: Saitama Ika Daigaku

Shigefumi Maesaki

Saitama Medical University: Saitama Ika Daigaku

Maeda Takuya ( $\nabla$ t_maeda@saitama-med.ac.jp)

Saitama Medical University: Saitama Ika Daigaku https://orcid.org/0000-0003-0912-4643

\section{Short report}

Keywords: SARS-CoV-2, COVID-19, CLEIA, Nasopharyngeal swab, RT-qPCR

Posted Date: May 7th, 2021 
License: (c) (i) This work is licensed under a Creative Commons Attribution 4.0 International License. Read Full License 


\section{Abstract}

A high-throughput, fully automated antigen detection test for SARS-CoV-2 is a viable alternative to reverse transcription polymerase chain reaction (RT-qPCR) for mass screening during outbreaks. In this study, we compared RT-qPCR for viral load and the VITROS ${ }^{\circledR}$ SARS-CoV-2 Antigen Test with reference to the results of the LUMIPULSE ${ }^{\circledR}$ SARS-CoV-2 Ag Test. Of 128 nasopharyngeal swab specimens taken from patients suspected of being infected with SARS-CoV-2, 49 were positive and 79 were negative according to RTqPCR. Consistent dose-dependent detection with VITROS ${ }^{\circledR}$ assay was successfully achieved when using nasopharyngeal swab specimens with $\mathrm{Ct}$ values of $\leq 32.0$, whereas the CLEIA-based the LUMIPULSE $^{\circledR}$ assay was able to detect lower viral loads compared with the VITROS ${ }^{\circledR}$ assay. Our results show that the performance of the VITROS ${ }^{\circledR}$ assay was satisfactory for the diagnosis of contagious COVID-19 patients in the clinical setting.

\section{Introduction}

Nucleic acid amplification (NAA) by reverse transcription polymerase chain reaction (RT-qPCR) has been used to diagnose COVID-19 and has the advantage of being able to monitor replication status based on viral load, but the testing procedure is complicated and relatively time-consuming. In addition, a positive result based on NAA does not always allow for a definitive conclusion as to whether the patient is contagious [1]. Recently, the emergence of SARS-CoV-2 variants such as P.1 and B.1.351, which contain a mutation repertoire within the Spike gene, has raised the possibility of emerging reinfections [2-4]. Furthermore, a previous report demonstrated that RT-qPCR can detect non-infectious SARS-CoV-2 RNA in nasopharyngeal $(\mathrm{Np})$ swab specimens in recovered adult patients up to 3 months after onset [5]. To overcome these problems, high-throughput diagnostic technology designed to detect active SARS-CoV-2 infection has become essential.

Recently, the VITROS ${ }^{8}$ SARS-CoV-2 Antigen Test (Ortho Clinical Diagnostics, Rochester, NY) was developed as a new diagnostic technology based on a two-step chemiluminescent enzyme immunoassay (CLEIA) and can be used to perform up to 130 tests per hour for the detection of active SARS-CoV-2 infection. This is a fully automated antigen detection test designed to detect active viral infection and is the first high-throughput COVID-19 antigen test to receive Emergency Use Authorization (EUA) from the US Food and Drug Administration (FDA). Recently, Favresse and colleagues demonstrated that the VITROS ${ }^{\circledR}$ SARS-CoV-2 Antigen Test completely aligned with RT-qPCR for Ct values up to 33 and found that the test had high specificity (100\%) [6]. However, evaluation in the clinical setting remains limited, so further studies are needed to confirm the real-world effectiveness of this technology.

In this study, we compared RT-qPCR in terms of viral load with two rapid antigen tests, namely, the VITROS ${ }^{\circledR}$ SARS-CoV-2 Antigen Test and the CLEIA-based LUMIPULSE® SARS-CoV-2 Ag Test (Fujirebio, Tokyo, Japan), to investigate their performance in the analysis of clinical Np swab specimens [7]. 
Np swab specimens were collected from patients suspected of being infected with SARS-CoV-2 at Saitama Medical University Hospital, Saitama, Japan, between December 22, 2020 and January 7, 2021. Each specimen was well suspended in 1,000 mL of phosphate-buffered saline (PBS) and used for the following analysis of COVID-19. Asymptomatic carriers were defined as confirmed COVID-19 patients with no history of clinical signs or symptoms on admission. The day of onset was defined as the first day of symptoms caused by COVID-19 in symptomatic patients or the day of the first positive RT-qPCR result using Np swab specimens in asymptomatic carriers.

Definitive diagnosis of COVID-19 was confirmed by RT-qPCR according to the nationally recommended protocol, using RNA extracted from $140 \mathrm{~mL}$ of the abovementioned suspension [8]. Briefly, RNA extraction was performed with the QIAamp Viral RNA Mini kit (Qiagen, Hilden, Germany) and RNA was finally eluted with $60 \mathrm{~mL}$ of Buffer AVL according to the manufacturer's instructions. Conventional RT-qPCR for specific amplification of the N2 gene of SARS-CoV-2 was performed using TaqMan-based real-time PCR with the following sets of primers and probe (2.4 $\mu \mathrm{M}$ of forward primer, $5^{\prime}$ - AAA TTT TGG GGA CCA GGA AC - 3'; $3.2 \mu \mathrm{M}$ of reverse primer, $5^{\prime}$ - TGG CAG CTG TGT AGG TCA AC - 3'; $0.4 \mu \mathrm{M}$ of probe; 5 ' - FAM - ATG TCG CGC ATT GGC ATG GA - BHQ- 3'). Each reaction was performed using QuantiTect Probe RT-PCR Kit (Qiagen) with cycling conditions of RT at $50^{\circ} \mathrm{C}$ for $30 \mathrm{~min}$, initial denaturation at $95^{\circ} \mathrm{C}$ for $15 \mathrm{~min}$, and 40 cycles of denaturation at $94^{\circ} \mathrm{C}$ for $15 \mathrm{~s}$, and annealing/extension at $60^{\circ} \mathrm{C}$ for $60 \mathrm{~s}$.

The VITROS ${ }^{\circledR}$ SARS-CoV-2 Antigen Test was also performed using the above Np swab specimens suspended in PBS. Briefly, $200 \mathrm{~mL}$ of the PBS suspension was added to $50 \mathrm{~mL}$ of the included VITROS $\circledast$ SARS-CoC-2 antigen sample treatment solution. Then, the assay was automatically performed with the VITROS ${ }^{\circledR} 3600$ automated immunoassay analyzer (Ortho Clinical Diagnostics). The analytical results were reported as signal/cutoff (S/C) values, where $\geq 1.0$ was defined as a positive test result and $<1.0$ as negative.

The LUMIPULSE® SASR-CoV-2 Ag Test was performed with the LUMIPULSE® G1200 (Fujirebio) according to the manufacturer's instructions. Briefly, each Np swab specimen was centrifuged at 20,000 x $\mathrm{g}$ for $5 \mathrm{~min}$, and the supernatant was used for subsequent analysis. The amount of SARS-CoV-2 antigen was determined based on the quantitative intensity of the reaction signal, where an antigen level of $\geq$ $1.34 \mathrm{pg} / \mathrm{mL}$ was defined as a positive test result and $<1.34 \mathrm{pg} / \mathrm{mL}$ as negative [7].

\section{Results}

A total of $128 \mathrm{~Np}$ swab specimens were collected from patients suspected of being infected with SARSCoV-2. Of the $128 \mathrm{~Np}$ swab specimens, 49 (38.3\%) were found to be positive by RT-qPCR, and the median Ct was 30.0 (interquartile range [IQR]: 24.0-35.0). The median age of patients diagnosed with COVID-19 was 58 years (IQR: 47-74), and 23 of these patients (46.9\%) were women.

In the VITROS $\circledast$ SARS-CoV-2 Antigen Test, all RT-qPCR-negative samples $(n=79)$ gave negative test results (100\% specificity), whereas antigens were detected in 37 of 49 RT-qPCR-positive samples (75.5\% Loading [MathJax]/jax/output/CommonHTML/fonts/TeX/fontdata.js PCR was $90.6 \%(116 / 128)$. In the LUMIPULSE® 
SASR-CoV-2 Ag Test, analysis revealed antigen reactivity in 1 of 79 RT-qPCR-negative samples (98.7\% specificity), whereas antigens were detected in 43 of 49 RT-qPCR-positive samples ( $87.8 \%$ sensitivity). Therefore, the overall concordance with RT-qPCR was also 94.5\% (121/128).

Figure $1 \mathrm{a}$ and $\mathrm{b}$ show the correlations between the $\mathrm{Ct}$ value obtained by RT-qPCR and the amounts of SARS-CoV-2 antigens determined by the VITROS $®$ SARS-CoV-2 Antigen Test and LUMIPULSE $®$ SASRCoV-2 Ag Test, respectively. Consistent dose-dependent detection was successfully achieved when Np swab specimens with $\mathrm{Ct}$ values of $\leq 32.0$ were used. All 6 samples that were positive according to the LUMIPULSE® SASR-CoV-2 Ag Test and negative according to the VITROS ${ }^{\circledR}$ SARS-CoV-2 Antigen Test had a Ct value $>32.0$. Table 1 summarizes the antigen detection rates for each quantified viral load from $\mathrm{Np}$ swab specimen according to the two tests. The detection rate was $85.5 \%(34 / 40)$ for $\geq 10.0$ copies $/ \mathrm{mL}, 96.8 \%$ (30/31) for $\geq 50.0$ copies $/ \mathrm{mL}$, and $100 \%$ (29/29) for $\geq 100.0 \mathrm{copies} / \mathrm{mL}$ in the VITROS $\circledast$ SARS-CoV-2 Antigen Test. The detection rate was $97.5 \%$ (39/40) for $\geq 10.0$ copies $/ \mathrm{mL}, 100 \%$ $(31 / 31)$ for $\geq 50.0$ copies $/ \mathrm{mL}$, and $100 \%$ (29/29) for $\geq 100.0$ copies $/ \mathrm{mL}$ in the LUMIPULSE $®$ SASR-CoV$2 \mathrm{Ag}$ Test.

Table 1

Positivity rate of SARS-CoV-2 antigen by viral loads in nasopharyngeal swab specimens

\begin{tabular}{|c|c|c|c|c|c|c|}
\hline \multirow[t]{2}{*}{ Viral load (n) } & & \multicolumn{2}{|c|}{$\begin{array}{l}\text { The VITROS } \AA \text { SARS-CoV-2 } \\
\text { Antigen Test }\end{array}$} & \multicolumn{2}{|c|}{$\begin{array}{l}\text { The LUMIPULSE® SASR-CoV- } \\
2 \\
\text { Ag Test }\end{array}$} & \multirow[t]{2}{*}{$p$-value } \\
\hline & & $\begin{array}{l}\text { Positive } \\
\text { samples }\end{array}$ & $\begin{array}{l}\text { Detection } \\
\text { rate }\end{array}$ & $\begin{array}{l}\text { Positive } \\
\text { samples }\end{array}$ & $\begin{array}{l}\text { Detection } \\
\text { rate }\end{array}$ & \\
\hline total & $\begin{array}{l}\mathrm{n}= \\
49\end{array}$ & $n=37$ & $75.5 \%$ & $n=43$ & $87.8 \%$ & 0.12 \\
\hline $\begin{array}{l}\geq 10 \\
\text { copies/mL }\end{array}$ & $\begin{array}{l}n= \\
40\end{array}$ & $n=34$ & $85.0 \%$ & $n=39$ & $97.5 \%$ & 0.05 \\
\hline $\begin{array}{l}\geq 50 \\
\text { copies } / \mathrm{mL}\end{array}$ & $\begin{array}{l}n= \\
31\end{array}$ & $\mathrm{n}=30$ & $96.8 \%$ & $\mathrm{n}=31$ & $100 \%$ & 0.32 \\
\hline $\begin{array}{l}\geq 100 \\
\text { copies } / \mathrm{mL}\end{array}$ & $\begin{array}{l}n= \\
29\end{array}$ & $n=29$ & $100 \%$ & $\mathrm{n}=29$ & $100 \%$ & NS \\
\hline NS, not signi & & & & & & \\
\hline
\end{tabular}

To assess the sensitivity of these assays according to the number of days after onset, 49 COVID-19 patients were divided into two groups: $\leq 9$ days after onset and $>10$ days after onset. The positivity rates of for each period were analyzed and the results are shown in Table 2. 
Table 2

Positivity rates of SARS-CoV-2 antigen by the number of days after onset

\begin{tabular}{|c|c|c|c|}
\hline & \multicolumn{2}{|l|}{ Days after onset } & \multirow[t]{2}{*}{$p$-value } \\
\hline & $\leq 9$ days $(n=35)$ & $\geq 10$ days $(n=14)$ & \\
\hline VITROS ${ }^{8}$ SARS-CoV-2 Antigen Test & $85.7 \%(30 / 35)$ & $50.0 \%(7 / 14)$ & 0.02 \\
\hline LUMIPULSE® SASR-CoV-2 Ag Test & $97.1 \%(34 / 35)$ & $64.3 \%(9 / 14)$ & 0.01 \\
\hline
\end{tabular}

\section{Discussion}

The VITROS ${ }^{\circ}$ SARS-CoV-2 Antigen Test can detect SASR-CoV-2 within 48 min and is capable of processing up to $130 \mathrm{~Np}$ swab specimens per hour. In this study, we demonstrated that the sensitivity of the VITROS ${ }^{\circledR}$ SARS-CoV-2 Antigen Test was $100 \%$ in samples with Ct values below 32.0 . It should be noted that unlike the LUMIPULSE® SASR-CoV-2 Ag Test, the VITROS® SARS-CoV-2 Antigen Test exhibits high specificity without the need for additional pretreatment procedures such as high-speed centrifugation. The VITROS ${ }^{\circledR}$ SARS-CoV-2 Antigen Test realizes high-throughput and rapid testing, does not require skilled technicians or multi-step procedures, and can be performed using equipment already installed in many laboratories. Thus, this test is a viable alternative to RT-qPCR and is suitable for mass screening during outbreaks.

Previous reports demonstrated that a "positive" NAA result including RT-qPCR reflects only the detection of viral RNA fragments and does not always indicate the presence of viable virus particles [9]. This is a clinically important point. In a larger cohort, Singanayagam et al. reported that $8 \%$ of samples with $\mathrm{Ct}$ values above 35.0 were positive for virus culture [10]. In addition, previous reports have also demonstrated that high $\mathrm{Ct}$ levels were associated with non-infectious SARS-CoV-2 [11, 12]. In our study, the VITROS $\circledast$ SARS-CoV-2 Antigen Test exhibited $100 \%$ sensitivity in Np swab specimens with a viral load above 100 copies/mL or Ct values below 32.0, as reported previously [6]. However, the CLEIA-based the LUMIPULSE ${ }^{\circledR \mathbb{Q}}$ SASR-CoV-2 Ag Test was able to detect lower viral loads compared with the VITROS ${ }^{\circledR}$ SARS-CoV-2 Antigen Test, but there was no statistically significant difference between the two tests (Table 2). These results indicate that the VITROS ${ }^{\circledR}$ SARS-CoV-2 Antigen Test was effective in detecting viable virus particles and may be useful for selecting contagious COVID-19 patients for infection control.

In this study, diagnostic agreement between RT-qPCR and both tests was significantly higher in samples collected in the early phase after symptom onset ( $\leq 9$ days) than in the late phase ( $>10$ days). Previous studies have demonstrated that no live virus is isolated from culture 9 days after of symptoms onset despite the prolonged RNA shedding detected with Np swab specimens $[13,14]$. Of the 5 discordant samples that were positive for RT-qPCR but negative for the VITROS $\circledast$ SARS-CoV-2 Antigen Test in the present study, all samples had Ct values above 33.0 and appeared to be in a non-contagious recovery period with low viral loads. 


\section{Conclusion}

In clinical practice, detecting the shedding of infectious live viruses is not only related to the diagnosis of COVID-19, but also to infection control in hospitals, including the decision on when to discharge patients. To summarize, our results show that the performance of the VITROS ${ }^{\circledR}$ SARS-CoV-2 Antigen Test was satisfactory for the diagnosis of contagious COVID-19 patients in the clinical setting. The test exhibited high sensitivity and specificity in the detection of SARS-CoV- 2 in samples with a Ct value of $\leq 32$ without the need for additional pretreatment procedures.

\section{Abbreviations}

SARS-CoV-2, severe acute respiratory syndrome coronavirus 2; COVID-19, coronavirus

disease 2019; NAA, nucleic acid amplification; Np swab: nasopharyngeal swab; RT-qPCR, reversetranscription quantitative polymerase chain reaction; $\mathrm{C}$, cycle threshold; CLEIA, chemiluminescent enzyme immunoassay; PBS, phosphate-buffered saline; IQR, interquartile range.

\section{Declarations}

Ethics approval and consent to participate

The study design and protocol were reviewed and approved by the Institutional Review Board of Saitama Medical University Hospital (Approval No. 20153.01).

\section{Consent for publication}

All authors approved the submission of the manuscript for publication.

Availability of data and materials

All data generated or analyzed during this study are included in this published article.

Competing interests

The authors have no conflict of interest.

Funding

No funding was allotted for this study.

Acknowledgements

Not applicable. 
TM is principal investigator of the study; TM and MM conceived the study; NM, MK, YK, and TM wrote the manuscript and analyzed the data; ST, KI, NT, and SM assisted in the writing of the manuscript and the data analysis; NM, YO, MK, YK, MM, RK, and TM performed the experiments. All authors read and approved the final manuscript.

\section{Author details}

${ }^{1}$ Department of Clinical Laboratory and ${ }^{2}$ Department of Infectious Disease and Infection Control, Saitama Medical University Hospital, Saitama 350-0495, Japan

\section{References}

1. Lanser L, Bellmann-Weiler R, Ottl KW, Huber L, Griesmacher A, Theurl I, et al. Evaluating the clinical utility and sensitivity of SARS-CoV-2 antigen testing in relation to RT-PCR Ct values. Infection. 2020;13:1-3.

2. Tegally H, Wilkinson E, Giovanetti M, Iranzadeh A, Fonseca V, Giandhari J, et al. Emergence and rapid spread of a new severe acute respiratory syndrome-related coronavirus 2 (SARS-CoV-2) lineage with multiple spike mutations in South Africa. medRxiv 2020. doi: https://doi.org/10.1101/2020.12.21.20248640.

3. Rani PR, Imran M, Lakshmi JV, Jolly B, Jain A, Surekha A, et al. Symptomatic reinfection of SARSCoV-2 with spike protein variant N440K associated with immune escape. J Med Virol. In Press.

4. Ramírez JD, Muñoz M, Ballesteros N, Patiño LH, Castañeda S, Rincón CA, et al. Phylogenomic Evidence of Reinfection and Persistence of SARS-CoV-2: First Report from Colombia. Vaccines. 2021;9(3):282.

5. Centers for Disease Control and Prevention. Duration of Isolation and Precautions for Adults with COVID-19. 10/19/2020. https://www.cdc.gov/coronavirus/2019-ncov/hcp/duration-isolation.html.

6. Favresse J, Gillot C, Oliveira M, Cadrobbi J, Elsen M, Eucher C, et al. Head-to-Head Comparison of Rapid and Automated Antigen Detection Testsfor the Diagnosis of SARS-CoV-2 Infection. J Clin Med. 2021;10(2):265.

7. Hirotsu Y, Maejima M, Shibusawa M, Nagakubo Y, Hosaka K, Amemiya K, et al. Comparison of automated SARS-CoV-2 antigen test for COVID-19 infection with quantitative RT-PCR using 313 nasopharyngeal swabs, including from seven serially followed patients. Int J Infect Dis. 2020;99:397-402.

8. Shirato K, Nao N, Katano H, Takayama I, Saito S, Kato F, et al. Development of genetic diagnostic methods for novel coronavirus 2019 (nCoV-2019) in Japan. Jpn J Infect Dis. 2020;73:304-7.

9. Wölfel R, Corman VM, Guggemos W, Seilmaier M, Zange S, Müller MA, et al. Virological assessment of hospitalized patients with COVID-2019. Nature. 2020;581(7809):465-9.

10. Singanayagam A, Patel M, Charlett A, Lopez Bernal J, Saliba V, Ellis J, et al. Duration of infortinucnoce and norralatinn with DT_PR nerlo throshold values in cases of COVID-19, England, 
January to May 2020. Euro Surveill. 2020;25:2001483.

11. La Scola B, Le Bideau M, Andreani J, Hoang VT, Grimaldier C, Colson P, et al. Viral RNA load as determined by cell culture as a management tool for discharge of SARS-CoV-2 patients from infectious disease wards. Eur J Clin Microbiol Infect Dis. 2020;39:1059-61.

12. Wölfel R, Corman VM, Guggemos W, Seilmaier M, Zange S, Müller MA, et al. Virological assessment of hospitalized patients with COVID-2019. Nature. 2020;581:465-9.

13. Cevik M, Tate M, Lloyd O, Maraolo AE, Schafers J, Ho A. SARS-CoV-2, SARS-CoV, and MERS-CoV viral load dynamics, duration of viral shedding, and infectiousness: a systematic review and metaanalysis. Lancet Microbe. 2021;2(1):e13-22.

14. Spinner CD, Gottlieb RL, Criner GJ, Arribas López JR, Cattelan AM, Soriano Viladomiu A, et al. Effect of Remdesivir vs Standard Care on Clinical Status at 11 Days in Patients With Moderate COVID-19: A Randomized Clinical Trial. JAMA. 2020;324(11):1048-57.

\section{Figures}

a)

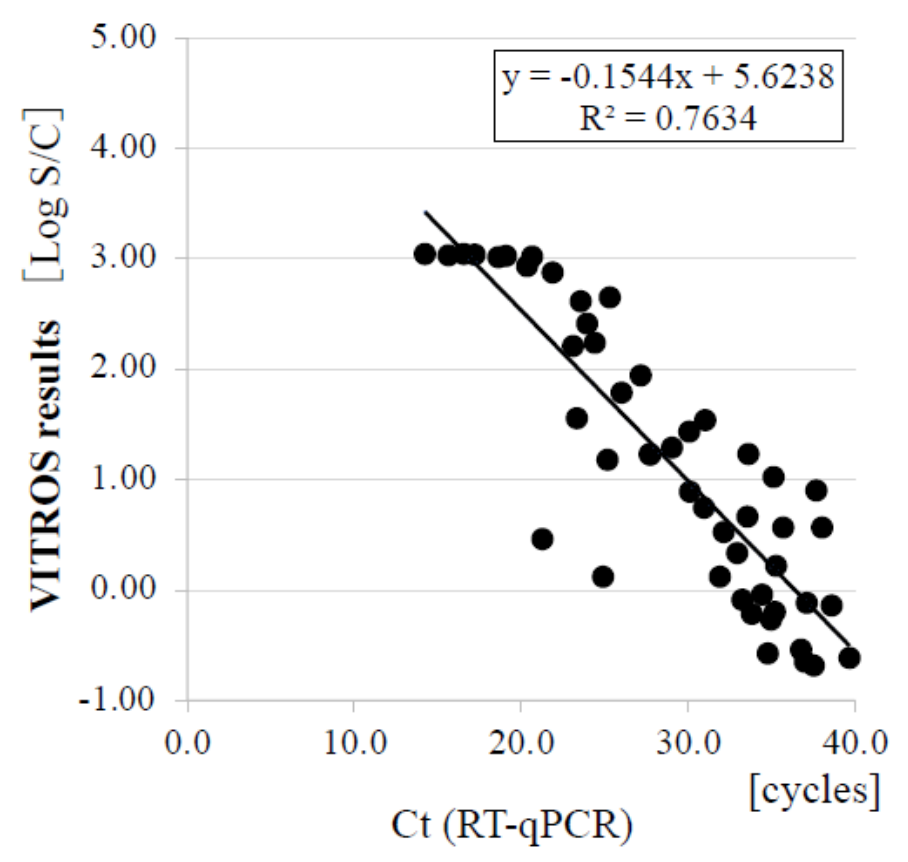

b)

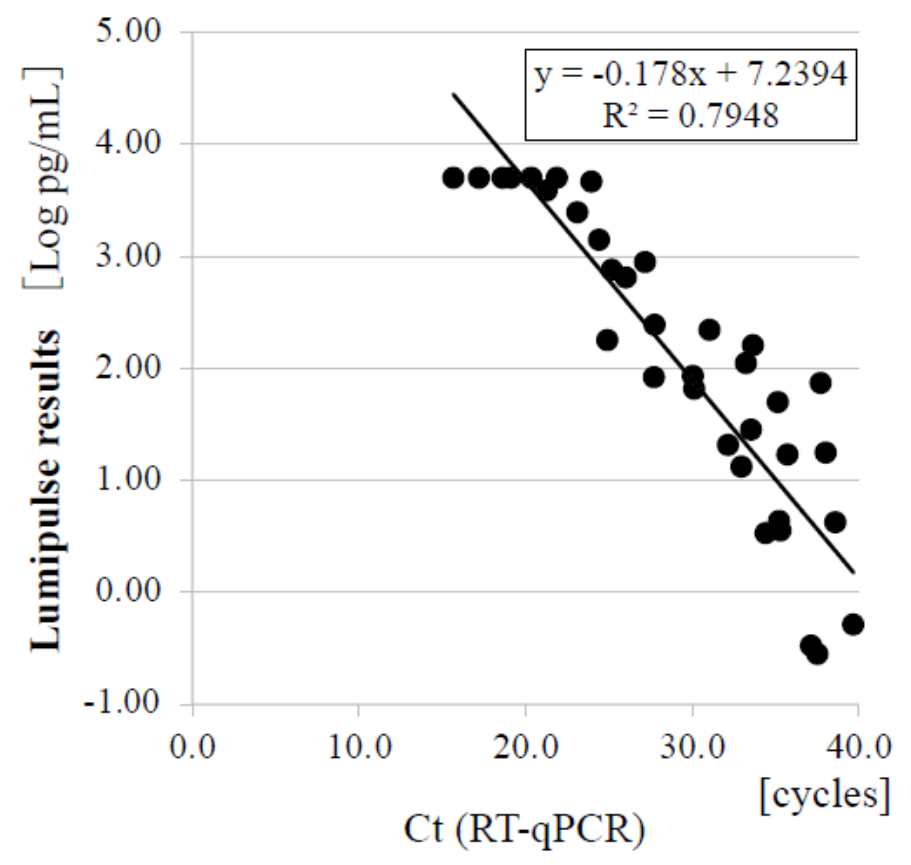

\section{Figure 1}

Correlations between $\mathrm{Ct}$ values obtained with RT-qPCR and antigen levels obtained by each automated antigen-detection test. The antigen level in (a) the VITROS $®$ SARS-CoV-2 Antigen Test and (b) the LUMIPULSE® SASR-CoV-2 Ag Test were plotted relative to RT-qPCR Ct value. The diagonal line shows the cut-off value. 